\title{
Damage Stability Behavior Analysis of a Cruise Liner Using Computer-Aided Design (CAD)
}

\author{
Nitonye Samson ${ }^{1}$, Feniobu Chris Feniobu ${ }^{2}$, Onyeagba Chukwukamagozi Whizfreeman ${ }^{3}$ \\ (Received: 17 July 2021 / Revised: 16 December 2021 / Accepted: 23 December 2021)
}

\begin{abstract}
- the paper uses more recent scientific and regulatory developments on the damage stability of ships to analyze damage stability of a vessel. The use of CAD in the analysis of several bulky and complex problems facing the maritime sector with respect to ship design and construction has helped reduce human error while more efforts are still made which will possibly eradicate these errors and ensure efficiency in the design and construction of ships. Some softwares are available in the market to support this analysis, as this paper searches to expose the effect on the design and the positive impact on design CAD can if properly integrated into the industry, to this end we used an already existing model of the vessel, made a model of it using the Bentley MaxSurf and then made floodable length analysis using various bulkheads at the fore, aft, and midship region. Thus, generating the graph of floodable length and the various allowable floodable length parameters at different stations.
\end{abstract}

Keywords — CAD, cruise liner, damage stability, floodable length, maxsurf, vessel.

\section{INTRODUCTION}

$\mathrm{T}_{\mathrm{r}-\mathrm{s}}$ he structure, equipment, shape, disposition, and special function of a ship all contribute to its safety; also, the nature of the cargo (which defines the danger inherent in its carriage) and other associated elements all contribute to its safety [1][2]. After considering all factors, everyone has the right and obligation to ensure the safe navigation of ships by implementing all measures imposed, particularly international rules, processes, and generally accepted practices in accordance with the United Nations Convention on the Law of the Sea (UNCLOS), developed by the International Maritime Organization (IMO), and enforced by Classification Societies. Classification Societies, on the other hand, are not guarantors of maritime safety or a vessel's seaworthiness because they do not have complete control over how the vessel is handled and maintained in between periodic assessments. Furthermore, the designer and shipbuilder are responsible for the ship's proper and efficient construction [3]. The shipowner, the shipowner's representatives, and the crew who run and maintain the ship daily are primarily responsible for the ship's safe operation for its intended service.

Ship stability is the ability of a vessel to return to an upright position after being heeled over by any combination of wind, waves, or forces from its operating environment, or compounded operator errors, whereas floatability is the ability of a vessel to support a given weight $\mathrm{W}$ by means of the hydrostatic pressure acting on the underwater surfaces, giving rise to the buoyancy force $\mathrm{B}$, to achieve a condition of upright equilibrium (stability),

Nitonye Samson is with Department of Marine Engineering, Rivers State University, Port Harcourt, Nigeria. nitonye.samson@ust.edu.ng.

Feniobu Chris Feniobu is with Department of Marine Engineering, Rivers State University, Port Harcourt, Nigeria.

Onyeagba Chukwukamagozi Whizfreeman is with Department of Marine Engineering, Rivers State University, Port Harcourt, Nigeria. the weight and force v. For hundreds of years, ship stability has been considered when it comes to naval construction. Historically, ship stability estimates were based on guesswork and were often related to a specific measurement system. Some of these ancient formulae are still used today in naval architecture textbooks.

Damage stability refers to a ship's capacity to float on water and re-establish its upright equilibrium position after sustaining structural damage. Following an accident, the most common damage is hull fracture, which results in flooding of the ship's compartments [6][7]. The ship may sink if several compartments are flooded to the point that there is insufficient buoyancy to keep the vessel afloat. The enormous expense of surface ship damages wreaked havoc on the nation's economy. This prompted naval architects to investigate the elements that contribute to shipwrecks at sea. Collison, Grounding, Poor design or structural failure, and Natural calamities are among them [8].

As a result, a ship's damage stability study is incorporated into its design process, ensuring that no or few problems occur during operation. Quantification of the ship's behavior, when damaged in the event of a breakdown or accident, was part of the damage stability analysis. Aspects of the design that will minimize or limit the damage caused by the failure. Two methods are used to examine a ship's behavior following damage: deterministic damage stability (lost buoyancy method and additional weight method) and probabilistic damage stability [9]. As a result, a ship's damage stability study is incorporated into its design process, ensuring that no or few problems occur during operation. Quantification of the ship's behavior, when damaged in the event of a breakdown or accident, was part of the damage stability design that will minimize or limit the damage caused by the failure. Two methods are used to examine a ship's behavior following damage: deterministic damage stability (lost buoyancy method and additional weight method) and probabilistic damage stability [9]. 
analysis. Aspects of the This work is aimed at reducing the bulky mathematical model and the need to recall formulas by the introduction of a computer-aided design during the behavior analysis, to help reduce the number of accidents seen at sea which is in line with the SOLAS conventions and to aid shipbuilders to gain more insight about the damage condition of the ship.

\section{A. Overview of Ship Stability}

The behavior of the body after it has been disturbed from its equilibrium state is referred to as stability [10]. A measure of a ship's ability to avoid capsizing in a specific loading circumstance. The loss of a ship's stability is depicted as a threat to navigational safety [11][12], hence there is always a link between a ship's stability and navigational safety. As a result, a study on this topic has gotten a lot of attention from the entire maritime community, resulting in the subject's present evolution to the integrated notion of "ship stability, dynamics, and safety," as it's known now [13]. The Archimedes Principle of Flotation states that a body immersed, or partially immersed, in a fluid at rest experiences a buoyancy force with a magnitude equal to the weight of the liquid displaced, acting vertically upwards through the centroid of the immersed volume of the body (the center of buoyancy) [14][15].

In physics, stability has to do with the body behavior after it has been disturbed from its equilibrium state, which is further classified into neutral, stable, and unstable, as this forms the bedrock of our definition of ship stability. Ship stability refers to a vessel's capacity to right itself after being tossed around by a mix of wind, waves, or other factors in its operating environment. It is known that ship overall stability can be classified into Intact Stability [16], Transverse Stability [17], The Righting Arm (Stable Equilibrium, Unstable Equilibrium, and Neutral Equilibrium). [18] Longitudinal Stability [19], Damage Stability [20].

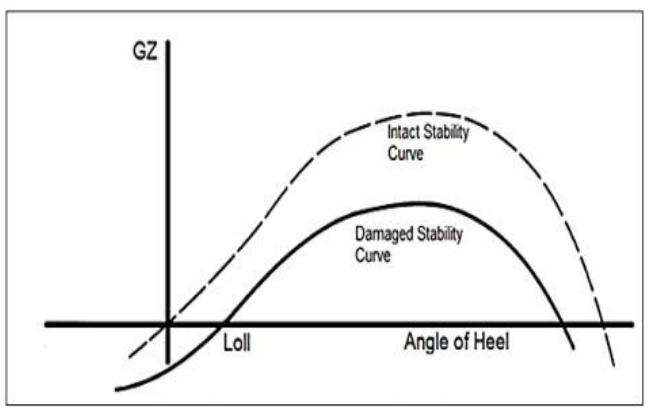

(a)

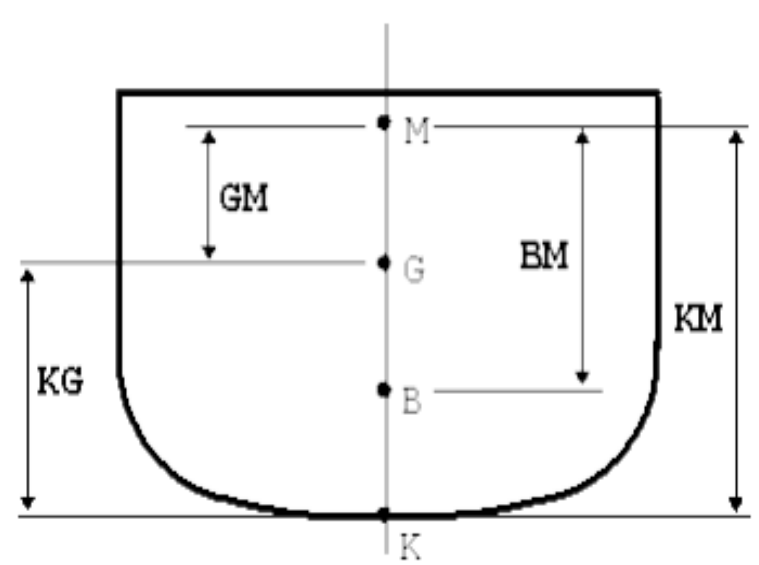

(b)

Figure. 1. GZ against Angle of the heel for loss of ship (a) [23], Linear Measurements in Stability (b) [5]

K - Keel; B - Center of Buoyancy; G - Center of Gravity; M Metacenter; KG - Height of the ships Center of Gravity the above Keel; KM - Height of Metacenter above the Keel; GM Metacentric Height (GM = KM - KG); GM is a measure of the ship's initial stability; BM - Metacentric Radius:

\section{B. Damage Stability}

When a ship's watertight hull is destroyed in a way that permits water to flood any compartment within the ship's hull, the study of damaged stability of a surface ship comes in handy [21]. This is investigated independently from intact stability since it modifies the ship's stability parameters, the magnitude of which depends on the extent of damage and flooding. The hull is split into a series of watertight compartments by bulkheads to limit the likelihood of this happening. In the case of damage, bulkheads cannot guarantee complete safety. Several compartments can be flooded if the hull is opened up for a long enough time (e.g., Titanic). Damage stability is clearly an essential concern in the construction of warships because they are expected to suffer harm from the adversary while in operation. The damage stability criterion varies from ship to ship, and SOLAS chapter II1 [22] specifies the requirements. It could be flooding in a single compartment, multiple compartments, or the engine 
room, for example. The vessel margin line shall not be submerged after the damage if all of the requirements are met. An imaginary line drawn $75 \mathrm{~mm}$ below the freeboard deck is known as the margin line. Damage and intact stability are two critical elements that influence the ship's overall stability. Damage is a possibility for any ship, but before we get into the methods for evaluating a ship's damaged stability, we'll define words relevant to damage stability and analyze the impacts of floods on a ship [23].

\section{Permeability}

This is the ratio of the volume of water entering a compartment to the volume of the compartment. A completely empty compartment would have a permeability of $100 \%$. A completely filled compartment will have a permeability of $0 \%$. Practically every compartment of a ship would have objects that would reduce the total volume that the flooded water could

occupy. Stiffeners, web frames, longitudinal brackets, beam knees, equipment, pipes, and outfits are among the goods. It's represented by the symbol and is usually given as a percentage. The Merchant Ship (Construction) Rules include formulas for calculating permeabilities for merchant ships. The table below shows some typical values. Although not exact, the same permeability values are commonly used as parameters when determining the area and inertias of the waterplane in terms of damage.

$$
\begin{aligned}
& \mu=\frac{v_{F}}{v} \\
& \text { Where; } \\
& \mu=\text { permability } \\
& v_{F}=\text { volume of the water that can flood the } \\
& \text { compartment } \\
& v=\text { volume }
\end{aligned}
$$

TABLE 1.

PERMEABILITY PERCENTAGE [24]

\begin{tabular}{ll}
\hline Space & Permeability (\%) \\
\hline Watertight compartment & 97 (warship), \\
& 95 (merchant ship) \\
Accommodation spaces & 95 (passengers or crew) \\
Machinery compartments & 85 \\
Cargo holds & 60 \\
Stores & 60 \\
\hline
\end{tabular}

\section{The Effects Of Flooding On A Ship}

The critical effect on the flooding on a ship will include amongst others; Change of Draft, Change of Trim, Change in Stability, heeling, Change in Freeboard, and loss in ship metacentric height. A ship is divided longitudinally into several watertight compartments in the idea of ship subdivision to limit flooding to one or more compartments in the event of damage. This prevents progressive flooding (i.e., flooding along the full length of the ship in the event of a single point of failure). Transverse watertight bulkheads are used to compartmentalize the space. Internal subdivisions with watertight transverse or longitudinal bulkheads, as well as some horizontal subdivisions-double bottoms in commercial ships and watertight flats in naval vesselsprovide the most efficient protection against damaging stability. Watertight bulkheads in Chinese junks were mentioned by Marco Polo near the end of the 13th century, therefore this type of protection is not new. [25]. The location of the bulkheads throughout the ship's length is mostly determined by the findings of flood-able length calculations performed during the ship's damaged stability assessment. Once their placements are determined, a variety of criteria come into play, such as the types of watertight bulkheads, their uniqueness in relation to their location, structural design, and so on. [26].

\section{E. Computer-Based Ship Design Analysis}

Several studies have been published in the last decade on reorienting engineering education to satisfy the industrial needs of industry [27], [28], [29], [30], [31], [32], [33], [34], [35], [36], [37], Since the early 1950s, the shipbuilding industry has used computer-based tools. Initially in accounting, the company expanded into certain design and manufacturing activities in the early 1960s, and by the early 1970s, it had developed the first CAD and CAM turnkey commercial systems. The rapidity with which this evolution occurred, as compared to, say, the current age of shipbuilding [28], is perhaps the most striking feature of it. In the previous five decades, a slew of computer-based solutions has been created to aid the ship design stage. Although there is no specified beginning point and various factors are interrelated, technologies such as TRIBON, IntelliShip, NUPASCADMATIC, FORAN, FRIENDSHIP, NAPA, MAXSURF, and FASTSHIP are now available to facilitate ship design. As a result, starting with a set of assumptions, the designers follow a spiral-like path to optimize the solution through an iterative process [29] [30], highlighting some specific situations of compartment flooding onboard a multipurpose cargo ship when the stability parameters deteriorate to the point where the ship fails to meet recommended criteria. The study's uniqueness stemmed from the fact that these ships are equipped with massive box cargo holds that, in the event of flooding, generate large free surface effects that have a significant detrimental impact on the ship's stability. As a result, four flood scenarios are shown, with the analysis of stability parameters depicted in accordance with the current damage stability regulations established by the international convention. The flooding scenarios described in this work were regarded as unique because the largest cargo hold of a multifunctional cargo ship was flooded, along with one side ballast tank, as a result of a collision with another ship. The fact that the ship's 
stability does not meet the recommended parameters in all of the anticipated flooding scenarios was stressed. Damage stability studies for multipurpose cargo ships can demonstrate that current damage stability requirements are insufficient for specific conditions. As a result, the need for additional damage stability requirements that have an impact on ship design may need to be considered [31]. According to Boulougouris et al. (2016), ensuring a sufficient level of safety from the standpoint of stability is typically considered a matter of design. However, it is impossible to ensure safety solely through design measures, and operational measures can then serve as a complementary tool for increasing the overall safety of the vessel efficiently and cost-effectively [32]. Vassalos et al. (2016) propose an alternative system for damage stability enhancement that involves injecting highly expandable foam into the compartment(s) undergoing flooding during the initial post-accident flooding phase, thereby enhancing damage stability and survivability of ships, particularly RoPax vessels, far beyond current design levels in the most cost-effective manner possible.

Tomić et al 2018 while using the MAXSURF suite to determine both the deterministic and probabilistic approach of damage stability was disturbed about the uneven results given off by both methods for a bow region damage scenario [33]. There is a trend toward moving away from deterministic methods and toward fully probabilistic approaches to the container ship stability problem. Because realistic scenarios are difficult to forecast using deterministic approaches, probabilistic methods are gradually replacing them. The influence of wave profile on ship righting arm is one of the probable stability failure issues addressed by a current effort at IMO, focused on the pure loss of stability [34], according to Coraddu et al 2011. The development of a computational tool to evaluate the influence of wave profile on ship metacentric height and righting arm is detailed, which will allow researchers to study alternative ship designs and loading situations in relation to wave profile length and steepness. Themelis \& Spyrou (2011) developed a viable method that takes advantage of the grouping properties of high waves. Rather than tackling the entire problem head-on, an effort is made to establish a path that combines the rigor of the deterministic approach in eliciting the nature of instability with appropriate analysis of the probabilistic seaway [35]. On the basis of a deterministic analysis of ship dynamics, critical wave encounters that could cause instability are identified, and a reasonable approach for determining the probability of such wave encounters is proposed.
Different capsize modes' probability were identified. The method is not biassed toward any one form of a mathematical model of ship motions, and it is simple to integrate into a risk assessment framework. The shift toward software packages should be considered as a new trend in our educational activity, according to Latorre \& Vasconcellos, 2002 [27][36]. It represents both a level of educational standardization and a challenge to conventional educational directions in naval design and marine engineering.

Younis et al 2019 studied the sensitivity of both the intact and damage stability properties and the limiting $\mathrm{KG}$ for intact and damage stability after changing the main dimensions of a passenger ship. They discovered that the stability properties are certainly dependent on the dimensions and shape of the vessel, and accordingly, determining the Limiting Deadweight moment and the limiting $\mathrm{KG}$ standards that meet specific criteria for damage and stability in the initial stages of vessel design $\mathrm{KG}$ are very important to measure the vessel's ability to withstand severe damage during service, requiring that the designer is aware of the relationship between this measure and the ship's dimensions[37][38].

For passenger ships, a decision support system with damage stability analysis has been identified as a crucial tool. Over the years, a variety of software programs have been developed and put into use without any direct link to any compelling demand outlined in the international regulatory framework. Following the Costa Concordia disaster, new laws were enacted that defined minimum specifications for a decision support system as an add-on to a loading computer. However, more complex technologies have lately been developed with the goal of providing crucial additional information on the expected growth of the damaged ship's stability.

\section{METHOD}

In this research a more modern approach of damage stability check and calculation is used [computer aided design (CAD) software] to calculate and analyze the damage stability of our vessel, using the deterministic method of damage stability analysis, which combines the loss of buoyancy and the addition of masses as our base. But before that, we would consider the concept of trim and sinkage during flooding. Table 1 shows the Parameter of the reference vessel;

TABLE 2.

VESSEL PARAMETER [24]

\begin{tabular}{ll}
\hline Parameters & Dimension \\
\hline Length overall & $311.1 \mathrm{~m}$ \\
Length between perpendiculars & 274.7 \\
Lload: & $275.359 \mathrm{~m}$ \\
Breadth extreme & $47.4 \mathrm{~m}$ \\
& \\
Breadth moulded & $38.6 \mathrm{~m}$ \\
& \\
Draught & $9.1 \mathrm{~m}$ \\
GT (ITC 69) & 138,194 \\
NT (ITC 69) & 108,645 \\
DWT & 11,132 \\
\hline
\end{tabular}




\begin{tabular}{ll}
\hline Freeboard & I \\
Beam & 47.4 \\
Depth & 24 \\
Builder & Kværner Masa-Yards \\
Decks & 15 \\
Deck clearance & 7 \\
\hline
\end{tabular}

\section{A. Trim And Sinkage During Flooding}

If a front compartment is exposed to the sea, the ship's buoyancy between the containing bulkheads is lost, and the ship sinks in the water until the rest of the ship provides enough buoyancy to restore equilibrium. The LCB's position changes at the same moment, and the ship must trim until $\mathrm{G}$ and $\mathrm{B}$ are in a vertical line again. The ship, which was previously moored at WOL0, is now moored at W1L1. Should W1L1 be higher than the deck where the bulkheads end at any point? (the bulkhead deck). It is necessary to use successive approximations to calculate the damaged waterline. Small-change assumptions do not hold true. The procedures of reduced buoyancy and added weight are the two options. The GM values are different, but the righting moment is the same.

1) Change in the draft calculation

$\Delta d_{F W D}=\frac{\left(\frac{L B P}{2} \pm L C F\right)}{L B P} \times C T$

Damage Displacement

= Intact displacement

- weight of sea water in damaged compartment

\section{2) Change Of Trim}

Water ingress in a compartment can be thought of as adding weight at any point along the ship's length. The ships trim changes because of this.

$$
\begin{aligned}
& \text { Change in Trim }=\frac{\text { moment changing trim }}{M C T 1 \mathrm{~cm}} \\
& \text { Change in trim }=\frac{100 w h L}{W G M_{L}} \\
& \text { MCT } 1 \mathrm{~cm}=\frac{W \times G M_{L}}{100 L} \\
& \text { where: } G M_{L}=B M_{L}
\end{aligned}
$$

3) Change In Stability

Flooding causes the ship's metacentric height to shift. The general statement of metacentric height can explain this.

$$
\begin{aligned}
& G M=K B+B M-K G \\
& K B=K M-B M \\
& B M=\frac{I}{\nabla} \\
& I=\frac{b d^{3}}{12}
\end{aligned}
$$

\section{B. Lost Buoyancy Method}

This technique considers that a flooded compartment does not provide buoyancy, i.e. the flooded compartment's volume no longer belongs to the vessel, but the weight of its structures is still included in the displacement. The 'remaining' vessel must adjust its position until force and moment equilibrium is restored. To determine this, let:
$W_{0} L_{0}=$ The original waterline of undamaged ship;

$W_{1} L_{1}=$ The waterline tangential to the margin line;

$\mathrm{W}_{0}$ and $\mathrm{B}_{0}=$ displacement and center of buoyancy of undamaged ship;

$W_{1}$ and $B_{1}=$ displacement and center of bouyancy of damaged ship

$G=$ center of gravity in the original and

trimmed condition

$b=$ center of bouyancy

Consider that the intact ship floats at $W_{0} L_{0}$ and then to be pulled down to $W_{1} L_{1}$ by some external force. Now consider the ship to be bilged and the amount of water $\mathrm{w}$ gaining access to the ship causes it to float at $W_{1} L_{1}$ with no external force. Then

$w=W_{1}-W_{0}$

taking moments about amidships, it gives

$w y=W_{1} y_{1}-W_{0} y_{0}$

$y=\frac{W_{1} y_{1}-W_{0} y_{0}}{w}$

\section{Added Weight Method}

Water entering the ship is treated as part of the ship in this technique. Permeability must be taken into account when calculating this weight, as well as the free surface of the water that has entered, but all hydrostatic data utilized are for the intact ship. Initially, the computation can be done as if there were no additional weight, but once the new waterline is set, the extra water that would enter the ship up to that waterplane must be factored in.

$$
\begin{aligned}
& \Delta_{F}=\Delta_{I}+\rho v \\
& \left(L C G_{F} \times \Delta_{F}\right)=\left(L C G_{I} \times \Delta_{I}\right)+(\operatorname{lcg} \times \rho \times v) \\
& T C G_{F} \times \Delta_{F} \times \Delta_{F}=t c g \cdot \rho \cdot v
\end{aligned}
$$

where the subscript $\mathbf{F}$ distinguishes the properties of the flooded vessel, and the subscript I those of the intact ship. Here, lcg refers to the longitudinal center of gravity of the flooding water volume, $\mathrm{v}$, and tcg is the transverse center of gravity. We assume $\mathbf{T C G}_{\mathbf{I}}=0$. When the trim and the heel are not negligible, we must consider the vertical coordinates of the centers of gravity of the intact ship and of the flooding water volume.

1) Determination of Floodable Length

To determine the maximum length of a compartment which can be flooded so as to cause a bilged ship to float at a water-line tangential to the margin line. We have from the equation of lost buoyancy,

If $\mu=100 \%$

then 
$l=\frac{v \times 100}{\mu \times A}$

\section{where}

$A=$ mean cross -

sectional area of the flooded compartment to $W_{1} L_{1}$ $v=$ volume of lost bouyancy $=w \times \frac{1}{1.025}$

$\mu=$ percentage permeability

$l=$ length of flooded compartment $=\frac{v}{A}$

2) Determination of ship draughts under damage condition

If the waterline of a ship floating at waterline WL to be damaged between two bulkheads forward and to lose buoyancy B tonnes. This buoyancy is lost up to WL and so the ship will sink until the lost buoyancy is recovered on the remaining intact form.

let $t=T P C$ of the intact waterplane

Let $T=$ original draught

Sinkage $=\frac{B}{T}(\mathrm{~cm})=\frac{B}{100 t}(\mathrm{~m})$

$S(m)$ approximately

Then

$\mathrm{T}+\mathrm{S}=$ appromixate draught when damaged considering a waterplane midway between $\mathrm{T}$ and $\mathrm{T}+\mathrm{S}$, i.e. a draught of

$$
T+\frac{s}{2} m
$$

the ship has lost buoyancy at a point y $(\mathrm{m})$ forward of midship and gained it a point $(\mathrm{m})$ aft of midship.

So

moment causing trim $=B(y+a)$

change of trim $=\frac{B(y+a)}{M C T 1 c m\left(\text { at } T+\frac{S}{2}\right)}$

$=\frac{C}{100} m$

Sinkage $=\frac{B}{100\left(\text { at } T+\frac{s}{2}\right)}=S_{1} m$

the new draught will be:

forward $=T+S_{1}+\frac{\frac{L_{p p}}{2}-2}{L} \times \frac{C}{100} m$

$A f t=T+S_{1}-\frac{\frac{L}{2}-a}{L} \times \frac{c}{100} m$

3) Vessel Design and Calculation Of Damage Condition Parameters Using MaxSurf

The MAXSURF suite will generate the floodable length and other damage stability parameters according to its program. To be able to analyze the damage behavior of a cruise liner we need a model vessel parameter and the Voyager of seas (DNV GL id:19902) registered under the DNV GL class society was used, which was modeled as a double hull cruise liner with longitudinal bulkheads and below are its dimensions.

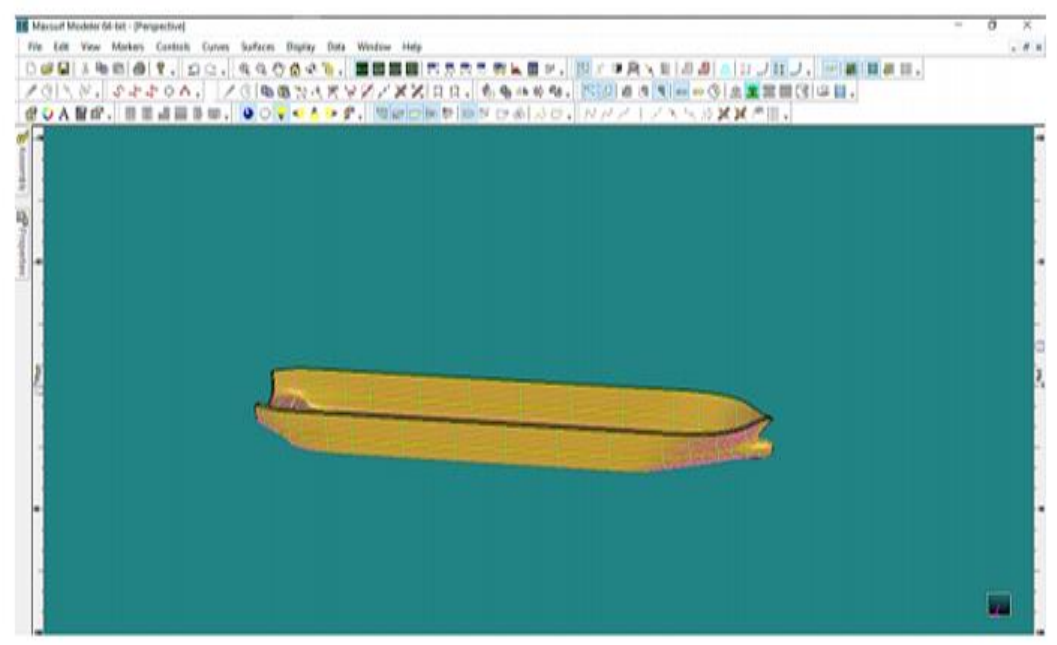

Figure. 2. Image of the model ship in 3D

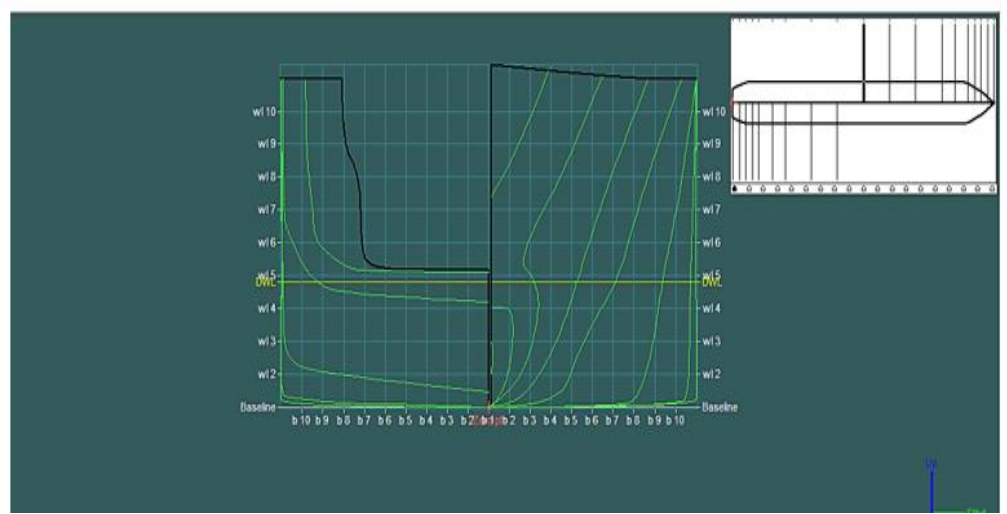

Figure. 3. Image of model ship body plan showing the AP and FP 


\section{Model Design}

To model the Voyager of Seas the first thing is to add a default surface, then we created a control point with respect to the software to get the bulbous bow and also trim the model starboard to the port side from the plan, body, and profile view of the model to get the shape of a vessel then we enter the LOA, depth and beam to replicate our main mirror vessel. Then we can proceed to run our floodable length analysis. Appendix A shows the model hydrostatics parameters as calculated by the software.

\section{RESULTS AND DISCUSSION}

Appendix B and Figure 4 show the results and graph of the floodable length for the displacement of $8000 \mathrm{t}$, 10000t,12000t. it was observed that the floodable length at the AP and FP are considerably low compared to the midship region, which implies the floodable length is higher, it is also understood that the allowable floodable length at higher displacements is lower compared to lower displacements. So, when the vessel was designed, care was taken on how to place compartments at the FP and AP. Although that all compartments passed the floodable length criteria, the need not to take the AP and FP lightly is necessary.

Similarly, Appendix C and Figure 5 show the results and graph of the floodable length of displacement for $10000 t, 12000 t, 14000 t$. This is an elaborated form of figure 4 at the increase of the displacements of the ship, it was observed that for optimization, the FP is a very critical region and any damage exceeding its floodable length is very disastrous.

Appendix D and Figure 6 shows the results and graph of the Floodable length table of various floodable lengths in the various station of the vessel at the displacement of $14000 t, 16000 t, 18000 t$.

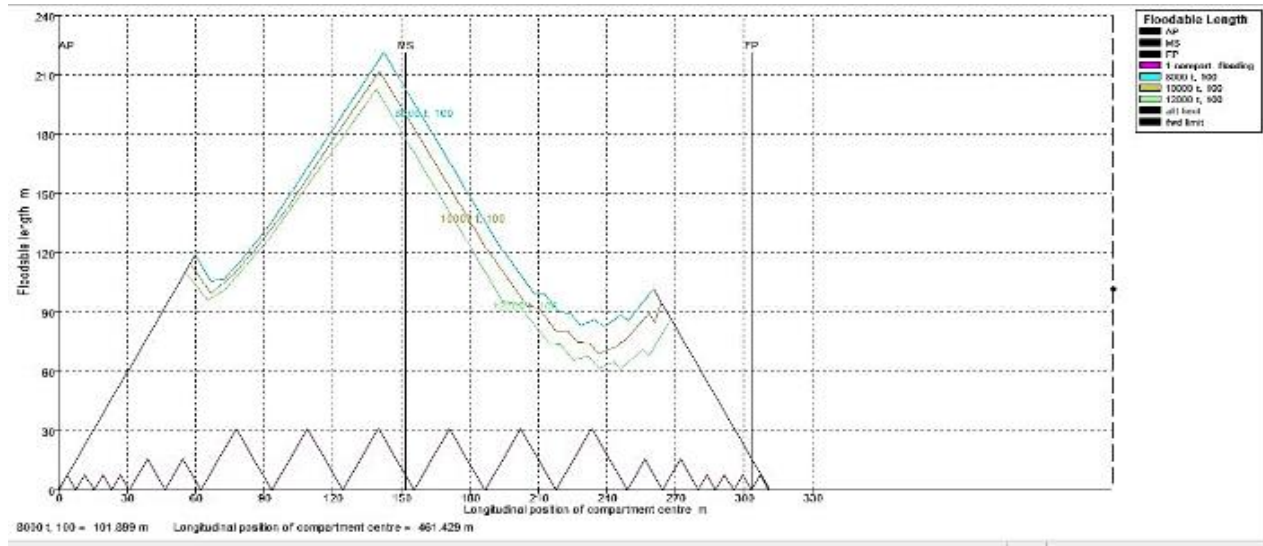

Figure. 4. floodable length of displacement 8000t, 10000t,12000t

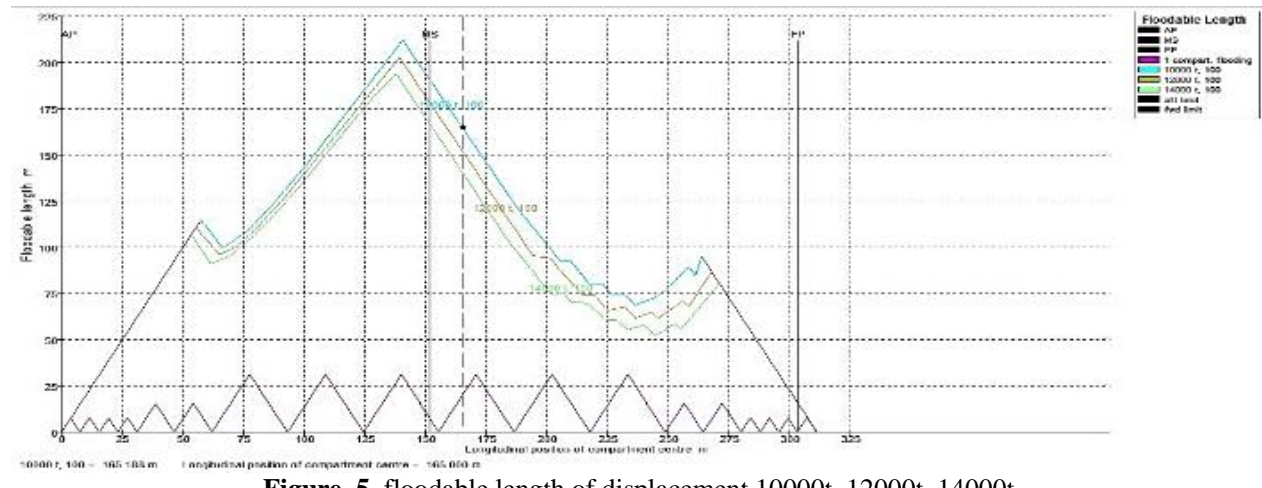

Figure. 5. floodable length of displacement 10000t, 12000t, 14000t

Just as in the preceding variations of displacement the more the displacement is increased the more the allowable floodable length FP and AP are reduced, still stressing even more on the need to take them more seriously during our design. Figure 7 shows the floodable length table of various floodable lengths in the various station of the vessel at displacement 8000, 10000,12000 (2 compartment flooding), so at further increase of displacements in figure7 elaborates on the need to maximize the bulkhead spaces we have at MS so that we can allow for accommodate our cargo, machinery, cruise accessories and passenger and crew alike to afford for a safe passage against any incident of damage, peradventure it happens we can ensure that minimal causalities. 


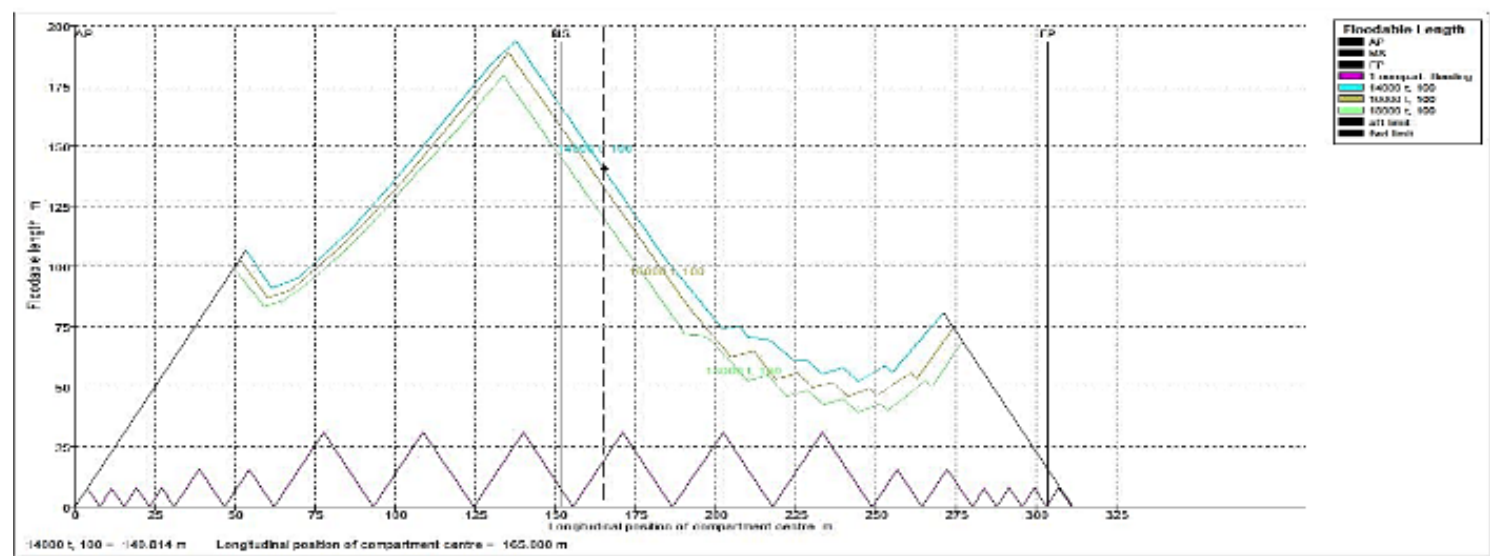

Figure. 6. Floodable length table of various floodable lengths in the various station of the vessel at displacement 14000, 16000,180000

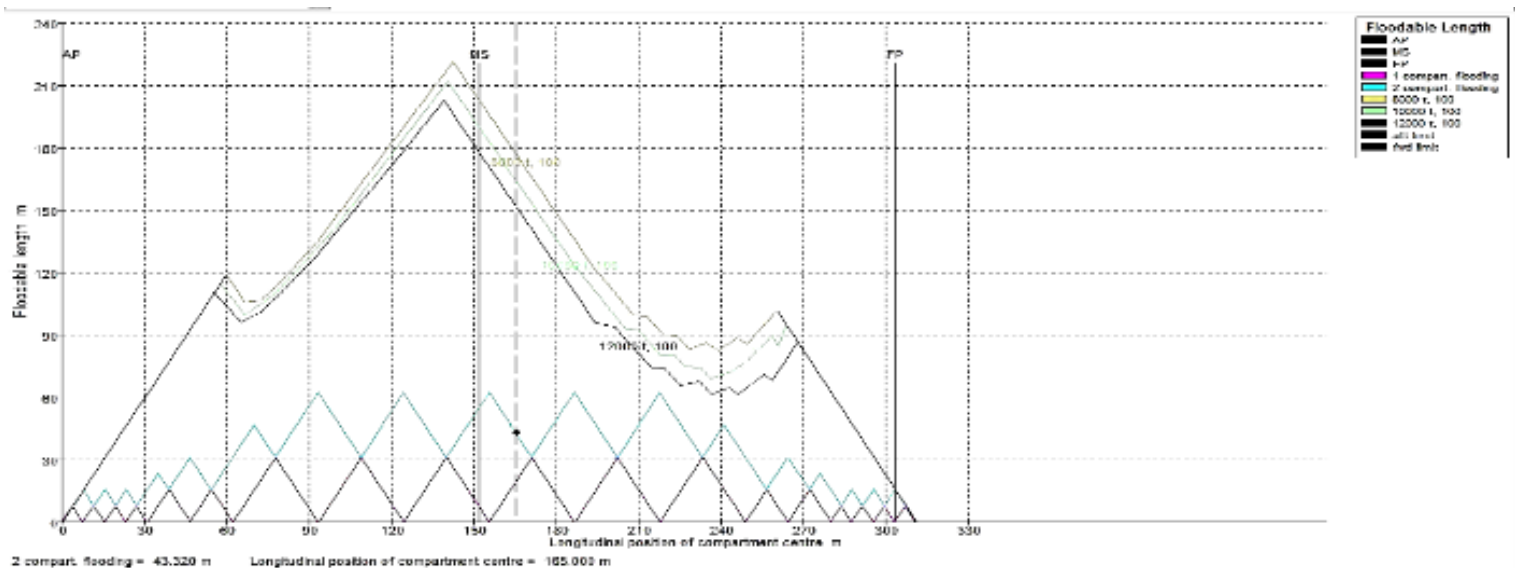

Figure. 7. Floodable length table of various floodable lengths in the various station of the vessel at displacement 8000, 10000,12000 (2 compartment flooding)

Figures 8 and 9 show the Floodable length table of various floodable lengths in the various station of the vessel at displacement 8000t, 1000t, 12000t and 10000t, $12000 t, 14000 t$ respectively. After an increase in overall displacement and addition of more adjacent compartments, it is observed that the floodable length at the fore perpendicular to the $3^{\text {rd }}$ compartment towards the FP will need to have the bulkhead moved slightly aft- wards or joined together in order to accommodate the actual floodable length not to get pass the allowable floodable length and also to allow for the vessel to pass design criteria. This also applies to Figure 8 as the actual floodable length is also the same as the allowable floodable length. As so this can be allowed but can cause problems in loaded conditions of that vessel.

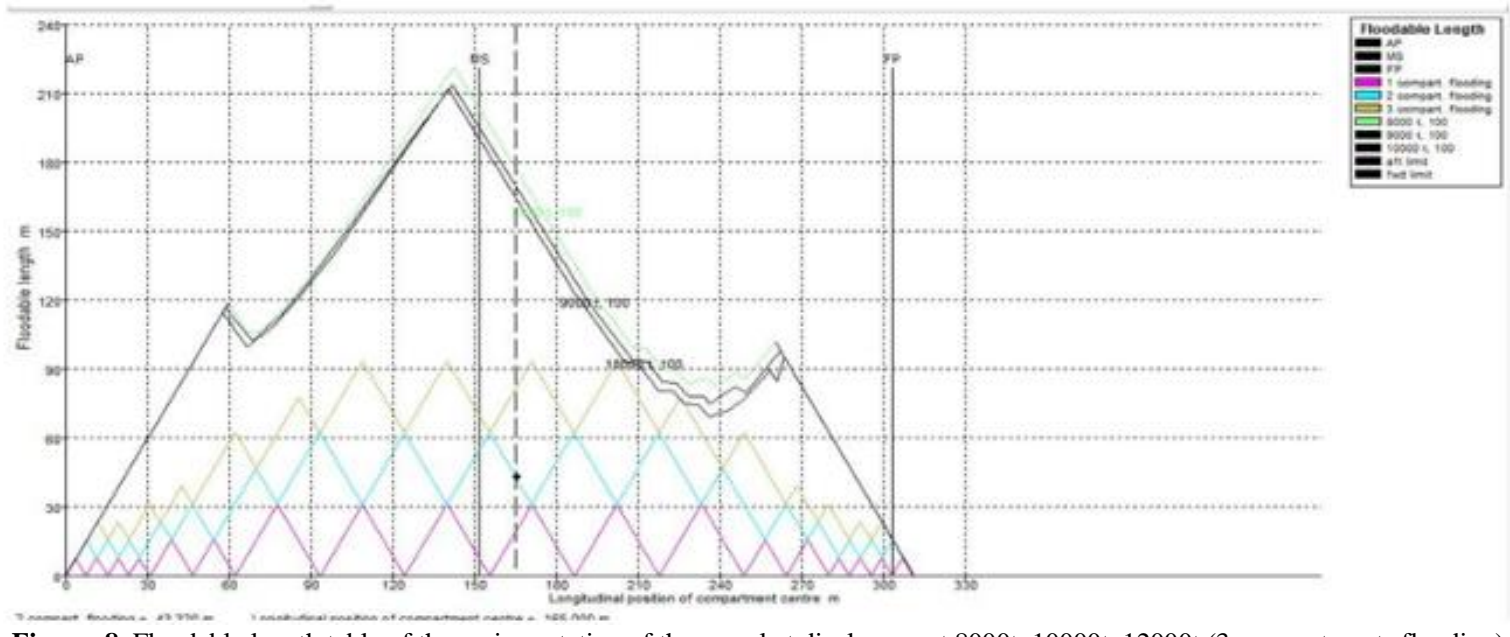

Figure. 8. Floodable length table of the various station of the vessel at displacement $8000 t, 10000 t, 12000 t$ ( 3 compartments flooding) 


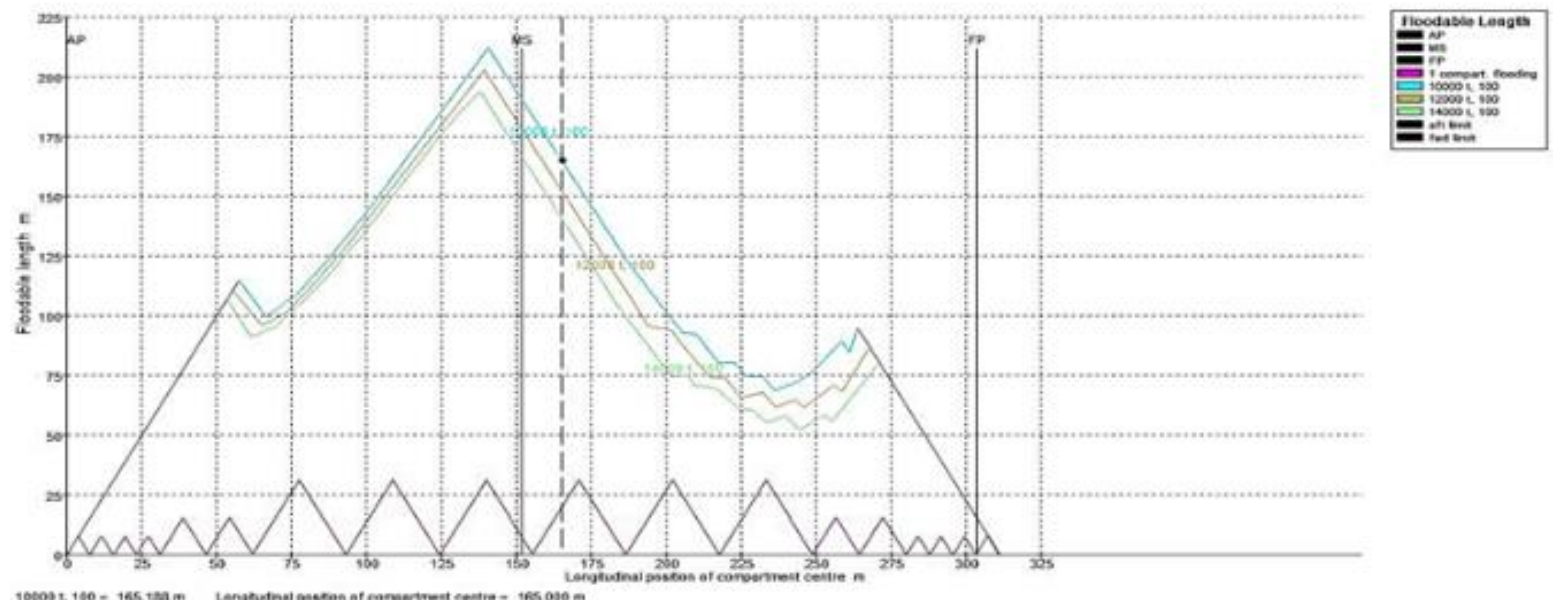

Figure. 9. Floodable length table of various floodable lengths in the various station of the vessel at displacement 10000t, 12000t, 14000t

Figure 9 can be considered and reevaluated because the actual floodable length of the $3^{\text {rd }}$ compartment is greater than the allowable floodable length, thus this vessel has to undergo re-evaluation, as to either remove the $3^{\text {rd }}$ compartment or change the positions of the bulkheads as to allow it to pass these criteria under the stated displacements which it's it failed the test. This is also applicable in figure 10. Figure 11 can be considered as bad for business because the actual floodable length is greater than the allowable floodable length, thus this vessel has to undergo re-evaluation, as to either remove the $3^{\text {rd }}$ compartment or change the positions of the bulkheads to allow it to pass these criteria under the stated displacements. So also in Figures 12 and 13.
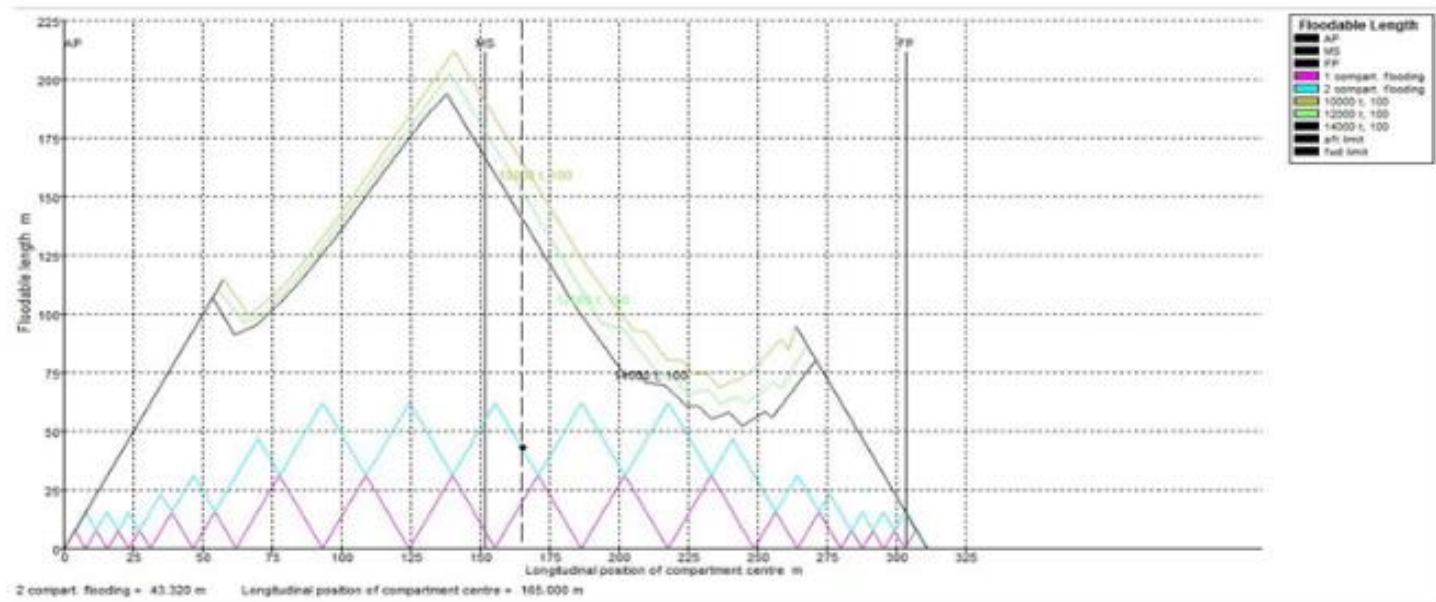

Figure. 10. Floodable length table of various floodable lengths in the various station of the vessel at displacement 10000t, 12000t, 14000t (2 compartments flooding)

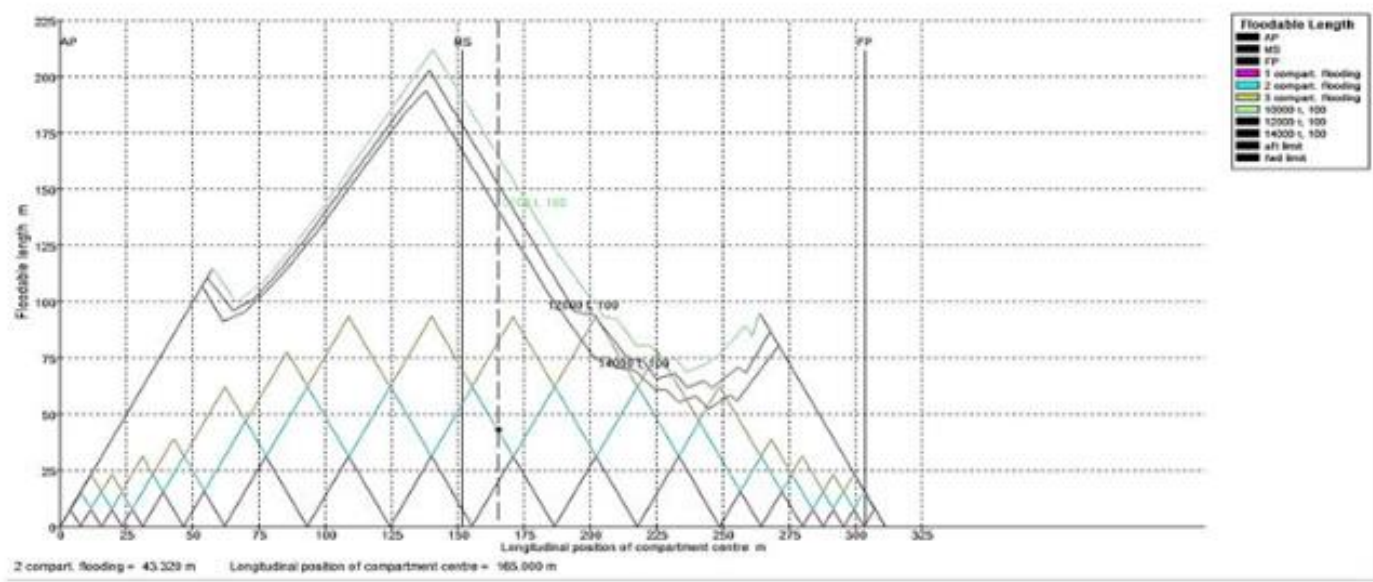

Figure. 11. Floodable length table of various floodable lengths in the various station of the vessel at displacement 10000t, 12000t,14000t (3 compartments flooding) 


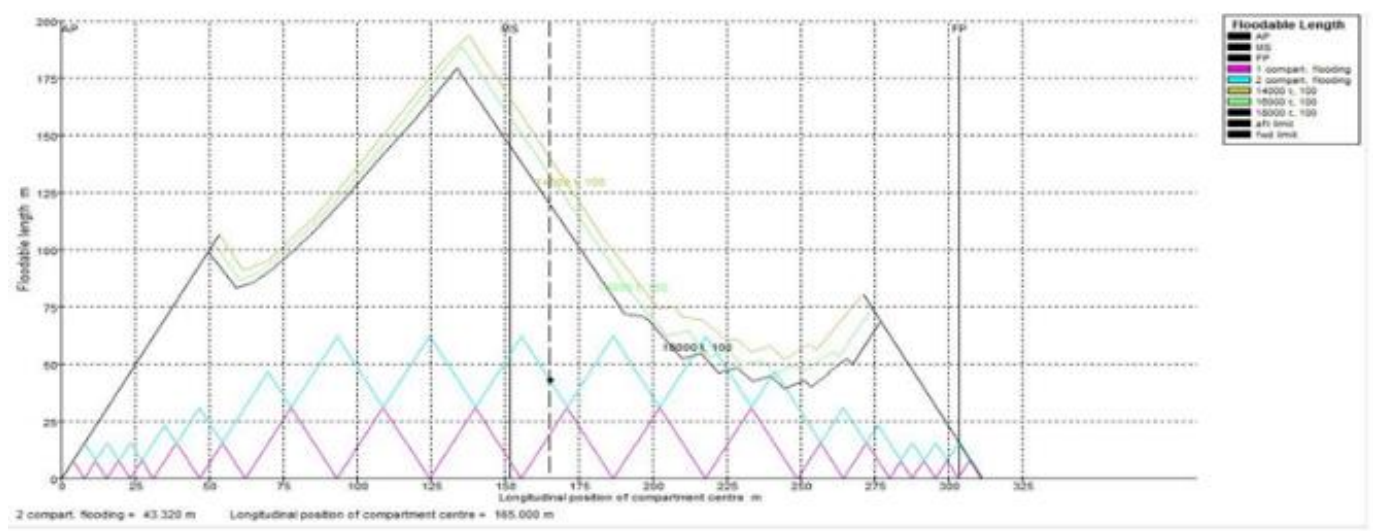

Figure. 12. Floodable length table of various floodable lengths in the various station of the vessel at displacement $14000 t, 16000 t, 18000 t$ (2 compartments flooding)

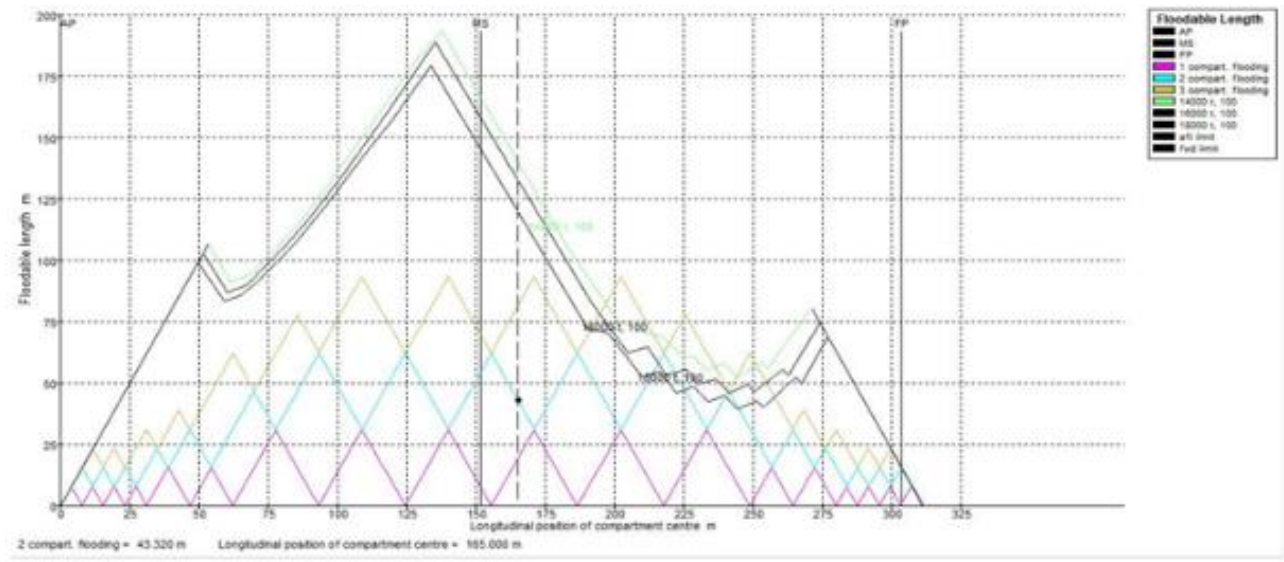

Figure. 13. Floodable length table of various floodable lengths in the various station of the vessel at displacement $14000 t$, $16000 t, 18000 t(3$ compartments flooding)

Doing this will ensure that our vessel is a safe move under certain damage conditions which concern the flooding of compartments and also enable our crew to know how to load the vessel as to anticipate flooding in case of any eventuality.

\section{CONCLUSION}

The undertaken systematic investigations of existing methodologies for evaluating ship's survivability in case of damage after collision revealed the merits, drawbacks, and open questions that, No matter how large or small damage is to the ship, understanding how to manage the phenomena is accomplished through the damage stability analysis, Floodable length determination is one of the criteria's a vessel must pass to be deemed seaworthy, so to provide for the safety of lives and properties at sea, vessel owners, naval architect, and crew must hold in high regards. Flooding onboard vessels are one of the most dangerous situations that can occur during the voyage. Those dangerous situations occurred because of accidents, such as collision, grounding, or structural breakdown, can lead to loss of ship stability or even capsize. With reference to damage calculations, it is clear that the shorter the compartments under the floodable length graph, the higher the floodable length of such compartments but the shortening of, any compartment must be handled carefully, especially, if the compartment in question is the engine room, as it is important to facilitate the fitting of equipment and movement of personnel through the compartment. The shortening may also increase the number of watertight bulkheads and consequently the lightweight of the ship. Also, it is important to note that the floodable length of a vessel is always higher at amidships and lower at the aft and for ends of the vessel. The flooding situations presented in this paper were considered particular situations due to the fact that the biggest compartment, of the cruise ship, was flooded together. The analysis of damage stability criteria was carried out for each particular case of flooding presented. The study is based on the idea to reveal the vulnerability of the cruise ships, with large compartments, as it provides engineering insights for life assessment of situations such as how to mitigate damage and how to assure that life and properties are safe and secure. Although floodable length no matter the level of safety it guarantees a lot of things are always at stake, during the time at sea and also due to humanity and its imperfections, this work is a call to move towards the probabilistic approach as the way forward but not the destination as much more can be done in the course of mitigating loss of lives and properties. Thus, the floodable length at the AP and FP shouldn't be taken lightly as this paper sheds more light on its imperativeness in the ship design. This work attempts to bring to light the efficiency of computer-aided design and how it makes life and marine engineer easier and also improves on the 
already existing model near accuracy to increase the efficiency to carry out his work.

\section{REFERENCES}

[1] Nitonye Samson, (2015). Stress and Resistance Analysis for the Design of a Work Barge, International Journal of Scientific and Engineering Research, (IJSER) India Vol.6 No: 5, (pn-1064974) (http://www.ijser.org)

[2] Adumene S., \& Nitonye, S., (2015). Numerical Modeling of Strength for Hull Form Component of a 700 Tonnes Self- Propelled Barge under Moment and Operational Loading, International Organization of Scientific Research Journal of Engineering, (IOSRJEN) India Vol. 5 No: 5, pp 45 -55 (http://www.iosrjen.org)

[3] Nitonye Samson and Sidum Adumene, (2015). Comparative modeling of hull form resistance for three ocean going vessels using methodical series, International Journal of Engineering and Technology, (IJET) Germany, 4 (4), 489-496; doi: 10.14419/ijet. v4i4.4948 (http://www.sciencepubco/index.php/IJET.com).

[4] Nitonye, S., \& Adumene S. (2014). Numerical and experimental analysis for the stability of a 2500 tonnes Offshore Work Boat. International Journal of Applied Science and Engineering, 3 (6), 1041-1053. (http://www.ijaser.com)

[5] Nitonye, S., Ogbonnaya, E. A., \& Ejabefio, K. (2013). Stability analysis for the design of 5000-tonnes Offshore Work Barge. International Journal of Engineering and Technology, 3 (9), 849857. (http://www.ijet.journal.org)

[6] Sameer, S. (2020, February 06). Damage stability analysis of ships. Retrieved February 20, 2021, from https://www.marineinsight.com/naval-architecture/damagestability-analysis-of-ships/

[7] Cheng, Y.F. \& Hirdaris, Spyros. (2012). Improvement of Ship Safety through Stability Research and Innovations. 10.13140/RG.2.1.2996.8724

[8] Nitonye, S., \& Adumene S. (2014). Numerical and experimental analysis for the stability of a 2500 tonnes Offshore Work Boat. International Journal of Applied Science and Engineering, 3 (6), 1041-1053. (http://www.ijaser.com)

[9] Ceyhun, A. C. (2014). THE IMPACT OF SHIPPING ACCIDENTS ON MARINE ENVIRONMENT: A STUDY OF TURKISH SEAS. European Scientific Journal, 10(August 2014), no 23, 1-14.

[10]WILSON, P. A. (2019). BASIC NAVAL ARCHITECTURE: Ship stability. SPRINGER INTERNATIONAL PU. doi:https://doi.org/10.1007/978-3-319-72805-6

[11]R Hanzu-Pazara et al 2016 IOP Conf. Ser.: Mater. Sci. Eng. 145 082019

[12] Initial stability. (2018, May 20). Retrieved March 08, 2021, from https://en.wikipedia.org/wiki/Initial_stability

[13]Bačkalov, Igor \& Bulian, Gabriele \& Cichowicz, Jakub \& Eliopoulou, Eleftheria \& Konovessis, Dimitris \& Leguen, JeanFrançois \& Rosén, Anders \& Themelis, Nikolaos. (2015). Ship Stability, Dynamics and Safety: Status and Perspectives.

[14]Biran, A,Pulido, R. L. (2014). Ship hydrostatics and stability. Amsterdam: Elsevier, Butterworth-Heinemann.

[15] Vance, J. E., \& John Davies, E. A. (1989, September 8). Dynamic stability. Retrieved February 17, 2021, from https://www.britannica.com/technology/ship/Dynamicstability\#ref64196

[16]Chakraborty, S (2021, February 05). Ship stability - understanding intact stability of ships. Retrieved March 09, 2021, from https://www.marineinsight.com/naval-architecture/intact-stabilityof-surface-

ships/\#: :text=First $\% 2$ C $\% 20$ Intact $\% 20$ Stability.,or $\% 20$ freely $\% 20 \mathrm{f}$ looded $\% 20$ by $\% 20$ seawater

[17]Chakraborty, S. (2019, November 29). Watertight bulkheads: Construction and regulations. Retrieved March 12, 2021, from https://www.marineinsight.com/naval-architecture/water-tightbulkheads-on-ships-construction-and-arrangement/

[18] Nitonye, S., \& Adumene, S., (2015). Predictive Analysis of BareHull Resistance of a 25,000 DWT Tanker Vessel. International Journal of Engineering and Technology, (IJET) United Kingdom, 5 (4), 194-198. (http://www.ijet.journal.org).

[19] Nitonye, S., Adumene, S. and Howells, U.U. (2017) Numerical Design and Performance Analysis of a Tug Boat Propulsion System, Journal of Power and Energy Engineering, 5, 11, 80-98. https://doi.org/10.4236/jpee.2017.511007

http://www.scirp.org/journal/jpee

[20]Tupper, E. C. (2013). Introduction to naval architecture Amsterdam: Butterworth-Heinemann, an imprint of Elsevier.

[21]DNV GL Vessel Register, Retrieved March 28, 2021, from https://vesselregister.dnvgl.com/VesselRegister/vesseldetails.html? vesselid $=19902$

[22] Startpagina Netherlands Regulatory Framework (NeRF) - Maritime (2020), Chapter II-1 Construction - Structure, subdivision and stability, machinery and electrical installations, Available online https://puc.overheid.nl/nsi/doc/PUC_1344_14/3/

[23] Soumya Chakraborty (2019), Ship Stability: Damaged Stability of Ships, available online https://www.marineinsight.com/navalarchitecture/ship-stability-damaged-stability-ships/

[24] Royal Caribbean International (2019) Voyage of the Sea, Available online https://www.royalcaribbean.com/cruise-ships/voyager-ofthe-seas

[25]Lewis, E. V. (1989). Principles of naval architecture. Jersey City, NJ: Society of Naval Architects and Marine Engineers.

[26]W ÄRTSILÄ Encyclopedia of Marine Technology (2019), Damage stability calculations, available online https://www.wartsila.com/encyclopedia/term/damage-stabilitycalculations

[27] Latorre, R. \& Vasconcellos, J. M. (2002). Introduction Of Software Packages in Naval Architecture, Marine and Ocean Engineering Courses. Introduction Of Software Packages in Naval Architecture, Marine and Ocean Engineering Courses, 1-8.

[28]Lamb, T. (2004). Ship design and construction (Vol. 1). Jersey City, NJ: Society of Naval Architects and Marine Engineers.

[29] Savio, G., Concheri, G., Meneghello, R., Angelo, L.D. (2012). COMPUTER AIDED SHIP DESIGN: A NEW TOOLS SUITE FOR MANAGEMENT, TRACING, UNFOLDING AND NESTING OF SHELLS. $2^{\circ}$ Congresso Nazionale De Coordinamento Della Meccanica Italiana - CDMI 2012, 1-12.

[30] Andrei, Cristian \& Stanca, Costel \& Acomi, Nicoleta \& Dumitrache, C \& Ancuta, Cristian. (2018). Damage stability analysis in particular flooding situations of a multipurpose cargo ship. IOP Conference Series: Materials Science and Engineering. 400. 082001. 10.1088/1757-899X/400/8/082001.

[31]Boulougouris, E., Cichowicz, J., Jasionowski, A., \& Konovessis, D. (2016). Improvement of ship stability and safety in damaged condition through operational measures: Challenges and opportunities. Ocean Engineering, 122, 311-316. doi: 10.1016/j.oceaneng.2016.06.010

[32] Vassalos, Dracos \& Boulougouris, Evangelos \& Paterson, Donald \& Kanerva, Markku. (2016). Designing for Damage Stability beyond Design Level

[33] Tomić, B., Turk, A., \&amp; Čalić, B. (2018). Recent advances in damage stability assessment with application on a container vessel. Journal of Maritime \&amp; Transportation Science, 2(Special edition 2), 167-184. doi:10.18048/2018-00.167

[34]Coraddu, A. , Gualeni, P., \& Villa, D. (2011). Investigation about wave profile effects on ship stability. Sustainable Maritime Transportation and Exploitation of Sea Resources, 143-149. doi:10.1201/b11810-25

[35]Themelis, N., \& Spyrou, K. J. (2011). Efficient probabilistic assessment of intact stability. Fluid Mechanics and Its Applications, 515-530. doi:10.1007/978-94-007-1482-3_29

[36] Fr'ed'eric Le Pivert, Abdelkader Tizaoui, Radjesvarane Alexandre, and Jean-Yves Billard (2015) Analytical Study of the Capsize Probability of a Frigate, 12th International Conference on the Stability of Ships and Ocean Vehicles (STAB 2015) At: Glasgow, Scotland, UK. Available online https://www.researchgate.net/publication/ 275828898_Analytical_Study_of_the_Capsize_Probability_of_a_ Frigate

[37] Younis, G., Abdelghany, R., Mostafa, M., \& El-Barbary, R. (2019) Sensitivity analyses of intact and damage stability properties to passenger ship's dimensions and proportions. Port-Said Engineering Research Journal, 23(1), 65-73. doi:10.21608/pserj.2019.32861

[38]Ruponen, P. , Pennanen, P. , \& Manderbacka, T. (2019). On the alternative approaches to stability analysis in decision support for damaged passenger ships. WMU Journal of Maritime Affairs, 18(3), 477-494. doi:10.1007/s13437-019-00186-8 
International Journal of Marine Engineering Innovation and Research, Vol. 6(4), Dec. 2021. 226-239 (pISSN: 2541-5972, eISSN: 2548-1479)

Appendix A: Model hydrostatics parameters as calculated by the software

\begin{tabular}{llll}
\hline S/N & Measurement & Value & Unit \\
\hline 1 & Displacement & 91792 & $\mathrm{t}$ \\
2 & Volume (displaced) & 89552.831 & $\mathrm{~m}^{\wedge} 3$ \\
3 & Draft Amidships & 9.1 & $\mathrm{M}$ \\
4 & Immersed depth & 9.117 & $\mathrm{M}$ \\
5 & WL Length & 284.876 & $\mathrm{M}$ \\
6 & Beam max extents on WL & 38.564 & $\mathrm{M}$ \\
7 & Beam max on WL & 38.564 & $\mathrm{M}$ \\
8 & Beam extents on WL of station with max area & 38.563 & $\mathrm{M}$ \\
9 & Beam on WL of station with max area & 38.563 & $\mathrm{M}$ \\
10 & Beam extents on WL amidships & 38.563 & $\mathrm{M}$ \\
11 & Beam on WL amidships & 38.563 & $\mathrm{M}$ \\
12 & Wetted Area & 15151.672 & $\mathrm{~m}^{\wedge} 2$ \\
13 & Max sect. area & 347.406 & $\mathrm{~m} \mathrm{~m}^{\wedge} 2$ \\
14 & Waterpl. Area & 10276.451 & $\mathrm{~m} \mathrm{~m}^{\wedge} 2$ \\
15 & Prismatic coeff. (Cp) & 0.905 & \\
16 & Block coeff. (Cb) & 0.894 & \\
17 & Max Sect. area coeff. (Cm) & 0.99 & \\
18 & Waterpl. area coeff. (Cwp) & 0.935 & \\
19 & LCB length & 149.986 & from zero pt. (+ve fwd) $\mathrm{m}$ \\
20 & LCF length & 148.49 & from zero pt. (+ve fwd) $\mathrm{m}$ \\
21 & LCB \% & 52.65 & from zero pt. (+ve fwd $\%$ Lwl \\
22 & LCF \% & 52.124 & from zero pt. (+ve fwd) \% Lwl \\
23 & VCB & 4.66 & $\mathrm{M}$ \\
24 & KB & 4.66 & $\mathrm{M}$ \\
25 & KG fluid & 0 & $\mathrm{M}$ \\
26 & BMt & 13.452 & $\mathrm{M}$ \\
27 & BML & 691.242 & $\mathrm{M}$ \\
28 & GMt corrected & 18.112 & $\mathrm{~m}$ \\
29 & GML & 695.902 & $\mathrm{~m}$ \\
30 & KMt & 18.112 & $\mathrm{~m}$ \\
31 & KML & 695.902 & $\mathrm{~m}$ \\
32 & Immersion (TPc) & 105.334 & tonne/cm \\
33 & MTc & 2104.691 & tonne.m \\
34 & RM at 1deg = GMt.Disp.sin(1) & 29014.793 & tonne.m \\
35 & Length:Beam ratio & 7.387 & \\
36 & Beam:Draft ratio & 4.23 & \\
37 & Length:Vol^0.333 ratio & 6.367 & \\
38 & Precision & High & 113 stations \\
\hline & & & \\
& & \\
& &
\end{tabular}


International Journal of Marine Engineering Innovation and Research, Vol. 6(4), Dec. 2021. 226-239 (pISSN: 2541-5972, eISSN: 2548-1479)

Appendix B: Floodable length table of various floodable lengths in various station of the vessel at displacement 8000 ,

\begin{tabular}{ccccc}
\hline Name & Long. Pos. m & Flood. Len m & Flood. Len m & Flood. Len m \\
\hline Displacement (t) & & 8000 & 10000 & 12000 \\
LCG m & & 150.691 & 150.612 & 150.556 \\
Permeability \% & 100 & 100 & -0.35 \\
st 0 & 0.000 & -0.35 & -0.35 & 15.21 \\
st 1 & 7.778 & 15.21 & 15.21 & 30.76 \\
st 2 & 15.555 & 30.76 & 30.76 & 46.32 \\
st 3 & 23.333 & 46.32 & 46.32 & 61.87 \\
st 4 & 31.110 & 61.87 & 61.87 & 92.98 \\
st 5 & 46.665 & 92.98 & 92.98 & 100.58 \\
st 6 & 62.220 & 114.50 & 106.89 & 129.32 \\
st 7 & 93.330 & 135.86 & 132.72 & 179.05 \\
st 8 & 124.440 & 189.99 & 184.66 & 170.98 \\
st 9 & 155.550 & 195.66 & 183.34 & 110.60 \\
st 10 & 186.660 & 135.73 & 123.58 & 74.05 \\
st 11 & 217.770 & 92.05 & 80.57 & 64.32 \\
st 12 & 248.880 & 86.26 & 76.68 & 79.96 \\
st 13 & 264.435 & 93.79 & 93.79 & 62.68 \\
st 14 & 279.990 & 62.68 & 62.68 & 47.12 \\
st 15 & 287.767 & 47.12 & 47.12 & 31.57 \\
st 16 & 295.545 & 31.57 & 31.57 & 16.01 \\
st 17 & 303.323 & 16.01 & 16.01 & 0.46 \\
st 18 & 311.100 & 0.46 & 0.46 & \\
\end{tabular}

Appendix C: Floodable length table of various floodable lengths in various station of the vessel at displacement $10000 \mathrm{t}, 12000 \mathrm{t}, 14000 \mathrm{t}$

\begin{tabular}{ccccc}
\hline Name & Long. Pos. $\mathrm{m}$ & Flood. Len $\mathrm{m}$ & Flood. Len $\mathrm{m}$ & Flood. Len m \\
\hline Displacement (t) & & 10000 & 12000 & 14000 \\
LCG m & & 150.612 & 150.556 & 150.510 \\
Permeability \% & 100 & 100 & -0.35 \\
st 0 & 0.000 & -0.35 & -0.35 & 15.21 \\
st 1 & 7.778 & 15.21 & 15.21 & 30.76 \\
st 2 & 15.555 & 30.76 & 30.76 & 46.32 \\
st 3 & 23.333 & 46.32 & 46.32 & 61.87 \\
st 4 & 31.110 & 61.87 & 61.87 & 92.98 \\
st 5 & 46.665 & 92.98 & 92.98 & 91.33 \\
st 6 & 62.220 & 106.89 & 100.58 & 125.89 \\
st 7 & 93.330 & 132.72 & 129.32 & 175.14 \\
st 8 & 124.440 & 184.66 & 179.05 & 159.22 \\
st 9 & 155.550 & 183.34 & 170.98 & 99.52 \\
st 10 & 186.660 & 123.58 & 110.60 & 68.35 \\
st 11 & 217.770 & 80.57 & 74.05 & 55.63 \\
st 12 & 248.880 & 76.68 & 64.32 & 70.11 \\
st 13 & 264.435 & 93.79 & 79.96 & 62.68 \\
st 14 & 279.990 & 62.68 & 62.68 & 47.12 \\
st 15 & 287.767 & 47.12 & 47.12 & 31.57 \\
st 16 & 295.545 & 31.57 & 31.57 & 16.01 \\
st 17 & 303.323 & 16.01 & 16.01 & 0.46 \\
st 18 & 311.100 & 0.46 & 0.46 & \\
\hline
\end{tabular}


International Journal of Marine Engineering Innovation and Research, Vol. 6(4), Dec. 2021. 226-239 (pISSN: 2541-5972, eISSN: 2548-1479)

Appendix D: Floodable length table of various floodable lengths in various station of the vessel at displacement 5000t,

\begin{tabular}{|c|c|c|c|c|}
\hline Name & Long. Pos. m & Flood. Len m & Flood. Len $\mathrm{m}$ & Flood. Len $\mathrm{m}$ \\
\hline Displacement (t) & & 14000 & 16000 & 18000 \\
\hline $\mathrm{LCG} \mathrm{m}$ & & 150.510 & 150.465 & 151.451 \\
\hline Permeability \% & & 100 & 100 & 100 \\
\hline st 0 & 0.000 & -0.35 & -0.35 & -0.35 \\
\hline st 1 & 7.778 & 15.21 & 15.21 & 15.21 \\
\hline st 2 & 15.555 & 30.76 & 30.76 & 30.76 \\
\hline st 3 & 23.333 & 46.32 & 46.32 & 46.32 \\
\hline st 4 & 31.110 & 61.87 & 61.87 & 61.87 \\
\hline st 5 & 46.665 & 92.98 & 92.98 & 92.98 \\
\hline st 6 & 62.220 & 91.33 & 87.85 & 84.54 \\
\hline st 7 & 93.330 & 125.89 & 121.83 & 118.83 \\
\hline st 8 & 124.440 & 175.14 & 170.60 & 164.62 \\
\hline st 9 & 155.550 & 159.22 & 150.75 & 138.13 \\
\hline st 10 & 186.660 & 99.52 & 91.84 & 79.20 \\
\hline st 11 & 217.770 & 68.35 & 54.79 & 52.50 \\
\hline st 12 & 248.880 & 55.63 & 48.05 & 41.69 \\
\hline st 13 & 264.435 & 70.11 & 56.09 & 51.63 \\
\hline st 14 & 279.990 & 62.68 & 62.68 & 62.68 \\
\hline st 15 & 287.767 & 47.12 & 47.12 & 47.12 \\
\hline st 16 & 295.545 & 31.57 & 31.57 & 31.57 \\
\hline st 17 & 303.323 & 16.01 & 16.01 & 16.01 \\
\hline st 18 & 311.100 & 0.46 & 0.46 & 0.46 \\
\hline
\end{tabular}

